FACTA UNIVERSITATIS

Series: Law and Politics Vol. 15, N 2, 2017, pp. 157 - 169

DOI: $10.22190 /$ FULP1701157Z

Original Scientific Article

\title{
WHAT VULNERABILITY? WHOSE VULNERABILITY? CONFLICT OF UNDERSTANDINGS IN THE DEBATE ON VULNERABILITY
}

\author{
UDC 17
}

\author{
Ivana Zagorac \\ Faculty of Humanities and Social Sciences, University of Zagreb, Croatia
}

\begin{abstract}
In this paper, I intend to explore the apparent difficulty in communication between two understandings of vulnerability: one that claims that vulnerability is a part of conditio humana, a feature closely connected to the facts of (human) embodiment and mortality, and the other which argues for the exclusivity of vulnerability and wishes to limit it to only those who are "more than ordinarily vulnerable". The first part of the paper outlines the main sources of disagreement between these two perspectives as may be read from scholarly literature and relevant ethics documents. The thesis of this text is that the conflict between the two perspectives can be resolved if the concept of vulnerability is understood in its complexity rather than as reduced to its negative aspects. In order to set grounds for the thesis, the second part of the paper examines what would constitute the concept of invulnerability. In the last part, three attempts at resolution of the conflict are examined. That which advocates for the redefinition of the conventional understanding of vulnerability is favored.
\end{abstract}

Key words: vulnerability, conflict, myth of invulnerability, negativity

\section{INTRODUCTION: THE CONFLICT}

An explicit consensus as to what constitutes vulnerability is still missing (Shi, 2001: 519; Shi, Stevens, 2010: 2; Ruof, 2004: 9). The conventional understanding holds that to be vulnerable "is to be somehow weaker, defenseless and dependent, open to harm and injury" (Gilson, 2011: 301). In the morally relevant sense, the term 'vulnerable' is used to note the susceptibility to being wronged or taken advantage of, i.e. the concern for someone's lack of ability to safeguard his/her own interest. Such a broad understanding

Received May $17^{\text {th }}, 2017 /$ Accepted May $22^{\text {th }}, 2017$

Corresponding author: Ivana Zagorac

Faculty of Humanities and Social Sciences, University of Zagreb, Ivana Lučića 3, HR-10000 Zagreb, Croatia

E-mail: izagorac@ffzg.hr 
of vulnerability tends to function as a background assumption that leads to two different basic concepts of vulnerability.

Firstly, the concept that views vulnerability as an ontological condition of our humanity and an essential characteristic of the human condition (Butler, 2004; Hoffmaster, 2006; Turner, 2006; Ricœur, 2007; Fineman, 2008; Gilson, 2011; Rogers, Mackenzie, Dodds, 2012; ten Have, 2016). As such, vulnerability is just another ability that can limit us, but also enable us, as a condition of openness to being affected both in positive and negative ways (Gilson, 2011: 310). A violent exploitation of one's vulnerability can, therefore, be seen as an attack on humanity, while helping and protecting vulnerable individuals or groups is praised as an act of humanity. This understanding of vulnerability is closely connected to the concepts of compassion, solidarity, and responsibility (Rendtorff, 2002; ten Have, 2015; Hoffmaster, 2006; Turner, 2006; Turner, Dumas, 2013), outlining vulnerability within the field of traditional philosophical ethics. The second understanding views vulnerability as context-dependent. It emphasizes the role socio-economic conditions play in exposing certain people more to threats and harm than others. This approach labels certain individuals or groups as vulnerable according to the presence or absence of particular characteristics. It acknowledges the universal vulnerability of (human) beings, but insists that only certain forms of vulnerabilities are worthy of special attention, i.e. that only "particularly vulnerable" subjects deserve special protection. According to this approach, we are all vulnerable, but only some are vulnerable in a way that seeks for an ethical response. This understanding of vulnerability is widely accepted in the field of medical ethics. Consequently, the field of medical ethics alone handles numerous applications of the descriptor 'vulnerable' which has become ubiquitous to the point that its utility has been changed (Hurst, 2008; Levine et al., 2004; Luna, 2009; Macklin, 2003; Schroeder, Gefenas, 2009).

Wrigley (2015) has listed some of the problems with these two understandings of vulnerability, as well as with attempts to construct some sort of overarching concept. His conclusion is that the concept of vulnerability itself does not add anything new to the already existing more familiar concepts or ethical concerns and that "any attribution of 'vulnerability" can be treated as nothing more than a form or marker signaling our attention to certain kinds of issues" (Wrigley, 2015: 8). According to Wrigley, we do not need to elaborate any further on the different understandings of vulnerability, because the concept itself is obsolete. Such an "eliminativist approach" is provocative, however I believe that the concept of vulnerability should not be too easily dismissed. It is true, which the following text will also show, that the consensus on the definition, scope, and practical implications of vulnerability is yet to be reached. The general belief that there are two different understandings of vulnerability which stand in conflict does not help in clarifying the matter. In recent years, the concept of vulnerability has attracted great attention of both scholars and policy makers (Ruof, 2004; ten Have, 2015; ten Have, 2016), but there have not been very many attempts at bridging the gap between the two understandings of vulnerability.

In this paper, I intend to explore the apparent difficulty in communication between these two perspectives on vulnerability. In the first part of the paper, I shall briefly present the main sources of disagreement as may be read from scholarly literature and relevant ethics documents. I do not aim at a comprehensive analysis here, but the presented findings will hopefully suffice to set grounds for the thesis of the second part of the paper. The thesis is that the communication channel between the two perspectives on vulnerability could be open, and the conflict between them resolved if the concept of vulnerability is understood in its complexity rather than simply reducing it to its negative aspects. Again, I do not intend to 
provide a full account of this claim in this paper, but to ground the thesis itself. To do so, in the last part of the paper I shall briefly examine three attempts at a resolution of the conflict between the two understandings of vulnerability that are presented in literature, and advocate for one of them.

\section{THE CONFLICT AS PRESENTED IN SCHOLARLY LiTERATURE}

In his recent article, Henk ten Have (2015) examined the tension between two basic perspectives on vulnerability, which he named 'philosophical' and 'political'. He recognized three substantial differences between them which could be, as the author suggested, resolved within the broader field of bioethics. First is the significance of human agency: the political perspective presupposes an action-driven individual, while the philosophical one claims that vulnerability is beyond the discourse of power and capacity. Next, the political perspective on vulnerability emphasizes the individual person, while the philosophical one focuses on the social nature of human beings. Finally, there is a conflict between the negative and positive sides of vulnerability: the political perspective uses the language of reduction of vulnerability and protection of the vulnerable (understanding vulnerability solely as negative), while the philosophical one pays attention to accounts of solidarity and respect (and thus provides a positive meaning to vulnerability) (ten Have, 2015). These two perspectives seem to stand in opposition. Some authors have even claimed that the conflict between them is so deep that one cancels the other. Luna (2009: 128), for example, fears that "naturalizing" vulnerability, i.e. thinking that it is normal or natural to be vulnerable (as suggested by the 'philosophical' perspective), might lead to abandoning the practice of special protection (which is the core of the 'political' perspective). Hurst (2008: 192; 2014: 52) has a similar concern: if we are all vulnerable, how does one justify special protection for some? For Forster et al. (2001: 1451) there is only one answer: if everyone is vulnerable, no one is entitled to special protection. Thus, from a political perspective the idea of shared vulnerability is purely ideological (ten Have, 2016: 125) with little or no application in practice.

On the other hand, many voices have been raised against certain aspects of the political perspective on vulnerability. In this perspective, vulnerability is understood as a state of existence that is characterized by a certain weakness or dependency, i.e. a situation in which the subject lacks resources to protect his/her interests. An ethical response of a stronger party is based on the belief that the deficiency of the vulnerable ought to be respected, not misused. In this way, special protection becomes the core of the political perspective on vulnerability. However, the concept of special protection has been criticized for numerous reasons. One reason is its rigidness as it assumes that every source of vulnerability influences "affected" subjects in a uniform way. Formalized calls for special protection (for example, those in some relevant ethics documents) seem to suggest exactly that. However, it is quite clear that a certain feature can make a person vulnerable in one context, but not in another. For example, women are indeed vulnerable subjects in certain societies (because of their restricted access to education, the labor market, health services, etc.), while in other parts of the world that might not be the case. Thus, it does not seem appropriate to declare that women in general are vulnerable, although in certain circumstances they indeed are for no other reason than being of the female gender. Challenging socio-economic conditions, the very young or very old age, illness, etc., can also induce one's vulnerability, however it seems wrong to claim that, say, older citizens are always and in every given context weak, 
defenseless, dependent, and in need of special protection. Such inflexibility and ungrounded generalization can easily lead to unwarranted paternalism (Zagorac, 2016: 1663-1667). A person who lives in poverty is not necessarily weak or dependent; such a person can still make very competent decisions and safeguard his/her interests. Moreover, the economically disadvantaged can be less vulnerable to impaired decision-making than their wealthier counterparts, or are at least no more vulnerable to it (Denny, Grady, 2007: 383; Grady, 2009: 22). Furthermore, Gilson has pointed out that there is a danger of making a shift "from thinking of vulnerability in terms of weakness to thinking about those who are vulnerable as weak" (Gilson, 2011: 311). One of her examples is the shift from the statement 'those living below the poverty line are vulnerable to disease' to the belief 'the poor are dirty, incapable of caring for themselves' (Gilson, 2011: 311). Uncritical acceptance of the call for special protection can open the path to stereotyping and stigmatization (Levine et al., 2004; Lange et al., 2013; Lyerly et al., 2008; Grady, 2009; Wild, 2012; Zagorac, 2016).

Another problem with vulnerability understood in terms of special protection as described above is that it is very hard to predict all the sources of vulnerabilities and their manifest variations which are supposed to signal a need for special protection. In order to set criteria broad enough to include as many variations of vulnerabilities as possible and subsequently provide the necessary protection for "affected" subjects, the category of vulnerability was constantly expanded. What followed was the inclusion of new vulnerable groups to the point where nearly everyone was considered vulnerable, which undermines the intention of special protection (Levine et al., 2004: 45; Forster et al., 2001: 1451). For our purposes here, it is important to note that the situation in which "nearly everyone is vulnerable" differs from the 'philosophical' claim that "we are all vulnerable". The tendency of listing new sources of vulnerabilities, which in turn increases the number of groups that are considered vulnerable, can be shown on the example of certain influential ethics documents. Authoritative ethics documents themselves have a long history of blurring the concept of vulnerability by trying to be more sensitive to the protection of the vulnerable (Coleman, 2009). Even though they aim at providing at least general guidance on how to deal with certain issues in practice, the most influential ethics documents in the field of (bio)medicine are not especially helpful when it comes to the question of the two perspectives on vulnerability.

\section{The CONFLiCT As PRESENTEd IN ETHICS DOCUMENTS}

Whilst vulnerability did not emerge explicitly as a concept in the earliest bioethics literature, documents such as the Nuremberg Code (1947), the Declaration of Helsinki (1964), and the Belmont Report (1979) were clearly aimed at providing protection for individuals who were vulnerable to harms incurred through participation in (medical) research. The Belmont Report (1979) was the first important international document that introduced the notion of vulnerability. This document lists three basic ethical principles - respect for persons, beneficence, and justice - which are considered particularly relevant to the ethics of research involving human subjects (Part B). Part C of the Belmont Report is concerned with the applications of these general principles and explicitly mentions vulnerable subjects; namely 'racial minorities', 'the economically disadvantaged', 'the very sick', and 'the institutionalized'. They are considered vulnerable because of "their dependent status and their frequently compromised capacity for free consent" (Part C3). CIOMS Guidelines (2002) emphasize a person's incapability of protecting his/her own interests, more precisely 
vulnerable persons are described as those who have "insufficient power, intelligence, education, resources, strength, or other attributes needed to protect their own interests" (Guideline 13). The Declaration of Helsinki (DoH) has gone through several revisions which have also affected the notion of vulnerability. First introduced in 1964, DoH included the concept of vulnerability in the fifth revision (2000). Vulnerability was here primarily understood as "consent-based", i.e. that version of DoH put forward the subject's capability for informed consent. Two subsequent changes of DoH $(2008 ; 2013)$ included substantial changes in the understanding of vulnerability. The current version of DoH (2013) describes the "particularly vulnerable" as "those who may have an increased likelihood of being wronged or of incurring additional harm" (Article 19). The present formulation makes a contribution to the "context-based" understanding of vulnerability as it focuses on the particular situation (medical research) and avoids fixed vulnerability determinants which could subsequently lead to stereotyping or stigmatization (for example on grounds of age, economic status, level of education, etc.). However, the underlying premise of all documents seems to be that the vulnerable are those who have fallen from the state of a peaceful selfsufficiency (or have not yet reached it) into a state of (or being at risk of) incapability of protecting their own interests. The message is, as already suggested by Henk ten Have (2015; 2016), that vulnerability is marked by certain negativity and should therefore be minimalized or eliminated.

The representative of the other perspective on vulnerability among ethics documents is the Barcelona Declaration (the European Commission's Basic Ethical Principles in European Bioethics and Biolaw, signed in Barcelona in 1998). This document wishes to oppose the Anglo-American approach to vulnerability: it uses 'vulnerability' as a noun, not as an adjective which could then be misused to label certain subjects; it wishes to emphasize the universal character of vulnerability, so it would be a unifying instead of a discriminatory factor among subjects; and aims at breaking the strong conceptual bonds between vulnerability and autonomy in favor of building responsibility and solidarity on grounds of appreciating vulnerability as an inherent feature of the human condition (Patrão Neves, 2009: 158-159). The Barcelona Declaration describes vulnerable subjects as "those whose autonomy or dignity or integrity are capable of being threatened" (Kemp, Rendtorff, 2008, 248; Rendtorff, 2002: 243). Vulnerability is here understood as a part of conditio humana, the feature which "expresses the finitude and fragility of life which, in those capable of autonomy, grounds the possibility and necessity for all morality" (Kemp, Rendtorff, 2008: 248; Rendtorff, 2002: 243). Authors of the Barcelona Declaration rely on contemporary European philosophy and refer to Ricœur, Levinas, and Habermas (Rendtorff, 2002: 241). The Barcelona Declaration wishes to move away from the dominant "vulnerability reducing agenda which aims to eliminate all vulnerability [...] in order to create perfect human beings" (Rendtorff, 2002: 237).

Some of the influential international ethics documents that address the concept of vulnerability have tried to implement both understandings of vulnerability. Article 8 of UNESCO's Universal Declaration on Bioethics and Human Rights (2005) consists of two sentences under the title "Respect for human vulnerability and personal integrity". The first sentence states that human vulnerability should be taken into account when applying and advancing knowledge and technologies, while the second one seeks for the protection of individuals and groups of special vulnerability and for respect of their personal integrity. Thus, both "universal" and "special" understandings of vulnerability have found their place in this article. This is further elaborated in the Report of the International Bioethics 
Committee of UNESCO on the Principle of Respect for Human Vulnerability and Personal Integrity (first published in 2011, final publication in 2013). The sole purpose of this report is to reflect on Article 8 of UNESCO's Declaration. Article 41 of the Report defines vulnerability as "a risk of a human being to be harmed in his or her physical and mental integrity". It further states that vulnerability is "an element of the human condition," an "essential feature of human nature," and "an inescapable dimension of the life of individuals" which "cannot be eradicated entirely." The Report argues that vulnerability beyond this kind of vulnerability constitutes "special vulnerability". The Report concludes that we all share responsibility in preventing every human being from having to find themselves in a position of special vulnerability (Article 44) (Zagorac, 2016: 1660-1661).

\section{THE CONCEPT OF INVULNERABILITY}

As we have seen earlier, the focus on special protection seems to be one of the key points of disagreement between the two understandings of vulnerability. In order to promote measures of special protection, one must presuppose either that some subjects are vulnerable while others are not, or that among us who are all "naturally" vulnerable certain individuals and groups exist that are "more than ordinarily" vulnerable, i.e. are exposed to "an increased risk of harm and wrongs" (Lange, Rogers, Dodds, 2013: 336). Special protection loses its exclusivity if it is addressed to all; it has to assume the existence of the invulnerable. The invulnerable does not need to be a fixed category of subjects; however, it seems unavoidable to presume the existence of such subjects when conceiving the notion of the vulnerable. What I wish to bring forward in this part of the text is the doubt that the concept opposite to vulnerability can be adequately conceived. If that turns out to be the correct assumption, i.e. that the opposite concept cannot be found, it would suggest that the concept of vulnerability itself is of a dialectic nature. Thus, any attempt of reducing it to its "negativity" (to use the term of Henk ten Have) would be the denial of its complexity. Henk ten Have (2015) listed three sources of disagreement between the two perspectives on vulnerability; I shall claim that the "negativity of vulnerability" represents the leading cause of the conflict.

Contrary to my previous statement, literature on vulnerability often presupposes that the concept of vulnerability stands in contrast to the concept of autonomy. In short, this antagonism is supposed to describe two mutually excluding forms of existence, or two extreme positions on the scale measuring the 'wholeness' of subjects: the perfect form of selfsufficiency cannot tolerate any weakness, i.e. the autonomous subject has no vulnerabilities. The antagonism between 'wholeness' and 'non-wholeness' seems to be an important part of the 'political' perspective on vulnerability. However, as the concept of autonomy is in itself very rich and multilayered, with forms that allow for its 'softer' understanding (as it is in the case with the concept of relational autonomy), it is questionable whether it could be contrasted to vulnerability. The solutions proposed in literature take different forms: from elimination of the concept of autonomy in favor of the concept of vulnerability (M. Fineman), the redefinition of autonomy so it could encompass vulnerability (relational autonomy), to the reorganizing of the relationship between the two (E. Levinas, P. Ricœur). The important point is whether or not we conceive vulnerability as being overall negative, as a mark of a certain deficiency, a sign of non-wholeness. Should this be the case, then a reference point has to be instituted. For that reason I shall use the term 'invulnerability' to cover whatever might be opposed to 'vulnerability'. 
The concept of invulnerable subject seems to be the background assumption of the 'political' vulnerability account. As already mentioned, the methodology of this approach roughly consists in specifying sources of vulnerabilities that further serve as indicators for introducing measures of special protection. In order to define such indicators, one must presuppose the existence of a subject who is "intact", i.e. who has not been "affected" by any of these factors. The special vulnerability account thus seems to rely on the presupposition that an invulnerable subject could be found, moreover, that such an individual is a paradigmatic example of a human being and should serve as a standard. This view defines certain features as clear signs of one's vulnerability (e.g. very young or very old age, serious illness, low socio-economic status, immigrant status, etc.), which are not present in an imagined paradigmatic (invulnerable) subject. As mentioned earlier, critics have expressed concerns that this simple and rigid classification methodology justifies paternalistic treatment of all those who are "infected" by a certain feature. Such practice can further lead to stereotyping, discrimination, stigmatization, and marginalization of those labeled as vulnerable.

As a response, Luna (2009) argues for a dynamic and relational concept of vulnerability which does not firmly claim that "someone is vulnerable, but [considers] a particular situation that makes or renders someone vulnerable" (Luna, 2009: 129). Regarding the concept of invulnerability (which Luna does not address in detail), this context-dependent approach would deny that the absolute invulnerability of a human being is or should be a norm. However, the concept of invulnerability is still present in the assumption that for more or less regular human activities we can always find individuals who will not be harmed or wronged in the process. In fact, despite Luna's criticism of a "baseline standard for a default paradigmatic research subject (a mature, moderately well educated, clear thinking, literate, self-supporting person)" (Luna, 2009: 123), her proposed account of layers, i.e. fluid notion of vulnerability in medical research, needs a certain standard for assessing one's vulnerability. This standard is not fixed but context-dependent. It seems that the comparable subject who in the same context would not be harmed or wronged serves as a reference point for determining "greater than ordinary vulnerability" of others (Rogers, Mackenzie, Dodds, 2012: 12). If the vulnerable moves to a more favorable context, a layer or two of his/her vulnerability is stripped off. For example, if a woman in a country that disrespects women's rights moves to a country that respects women's rights. In a new country, however, her rights as a woman might be respected, but she has acquired the status of an immigrant which adds a new layer to her vulnerability. Her status does not match with the reference point: the paradigmatic exemplar of invulnerable subject (in this case a member of the majority) within a given context. In the course of time she might reach the status of a majority member which would remove all layers of vulnerability once related to her political and social status, however if she becomes seriously ill, this makes her vulnerable in comparison to her healthy fellow citizen. The point I wish to make here is that even a concept of vulnerability that fosters a context-dependent understanding of vulnerability presupposes a reachable standard, a paradigmatic exemplar of a human being that is not affected by a certain feature.

Luna's (2009) account of layers, accepted by many authors in different forms, aimed at showing that the context makes us vulnerable. On that point, Schroeder and Gefenas (2009) offer a more nuanced understanding: we are all equally fragile to the possibility of being harmed (e.g. becoming ill), but we are not all equally exposed to that threat nor do we all have the same resources available to protect ourselves (e.g. to pay for prevention medicaments) (Schroeder, Gefenas, 2009: 115-116). Their approach aims at providing grounds for special 
protection by differentiating between the probability of incurring an identifiable harm and the ability (or lack of it) to protect oneself (Schroeder, Gefenas, 2009: 117). This seems to point to the conclusion that instead of making us vulnerable, as suggested by Luna (2009), the context actually only reveals our vulnerability. If we are all receptive to harm and wrongs, then the question of the context is nothing more than a question on how intense, how complex, and in which form we will experience being vulnerable. Insomuch the conclusion of Martin et al. (2014) holds: we should focus on the likelihood of experiencing harm and wrongs because here is where the difference lies. However, this proposal can also only be valid if it includes a reference point: the degree of 'likelihood' can be estimated only in comparison to 'nolikelihood'. Consider the case of a natural catastrophe: it definitely increases the likelihood of experiencing harm and wrongs, but in assessing one's vulnerability this feature is relevant only if, everything else being equal, individuals exist who are not endangered by the catastrophe. In the case of a catastrophe on a global scale, the reference point is lost and the fact that we are all experiencing the same level of intoxication, radiation, very high or very low temperatures, or whatever the consequences might be on our natural habitat and our bodies, becomes irrelevant for determining the vulnerability of an individual. Moreover, it becomes irrelevant for defining special vulnerability per se. The invulnerability standard is what enables special vulnerability account: detection of those who have failed to reach it and consequent justification of special protection of those "fallen" subjects (Kottow, 2005). This approach neither questions how or why there has been a shift from the standard in the first place, nor does it wish to support vulnerable subjects in reaching their invulnerable mode of existence. It suggests that vulnerability is to be avoided, while invulnerability is a desirable state of existence. According to the thesis of this text, it is exactly such a simplified view of vulnerability that represents the core of misunderstandings between the two perspectives on vulnerability. In the last part of the text, I shall briefly present three different attempts at finding a resolution to this conflict: one that understands vulnerability as negative, one that sees it as positive if used for the good, and one that views vulnerability as a potential for both negative and positive outcomes. Naturally, these simple qualifications do not do justice to the complexity of each suggestion, nevertheless I take them as being generally correct.

\section{ATTEMPTS AT RESOLUTION}

Samia A. Hurst (2008) assumes that a definition of vulnerability should consist of a claim to special protection. A definition that includes humanity, such, for example, as the one provided in the Barcelona Declaration, is thus considered as too broad as it does not provide reasons for special protection. On the other side of the spectrum, according to Hurst, there are restrictive definitions, grouped as consent-based ("being at risk of giving faulty consent") and harm-based ("susceptibility to compound additional harm"), which Hurst considers to be of insufficient comprehensiveness. Her proposal is an extensive combination of the previous two approaches: vulnerability is a claim to special protection which should be understood as an identifiably increased likelihood of incurring additional or greater wrong. The comparative advantages of this definition are recognized in the focused attention on the characteristics of the environment rather than on the characteristics of the subjects; in broadening the scope of vulnerability as it remains open to the multiple nature of potential wrongs and sources of greater likelihood of suffering them; it conceptually dislocates the claim to special protection of the vulnerable outside of vulnerability itself to some other 
valid source; and practical usefulness in both research ethics and clinical ethics. As one of the limitations of the proposed definition, Hurst states that it excludes forms of vulnerability associated in general to being human, that is, the definition stays within the spectrum of special vulnerability (Hurst, 2008). The controversy concerning the two disparate views on the scope of vulnerability is addressed in a later article. Here the authors Martin, Tavaglione, and Hurst (2014) characterize this problem as a conflict between the idea that vulnerability encompasses everyone and the view that it should be restricted to just those requiring special protection. The authors believe that this conflict is actually a philosophical pseudo problem: the two views on vulnerability refer, in fact, to the same concept with different likelihoods of manifestation. The aim of their study, then, is to broaden the definition proposed earlier by Hurst (2008) and to provide a more general account of vulnerability for bioethics (Martin et al., 2014: 54). Their approach in clarifying intrinsic (human) vulnerability centers on interests. Two groups of interests are recognized: welfare interests, which should be distinguished from preference interests, and agency interests. A subject can be considered vulnerable when either their welfare or agency interests are frustrated, regardless of the source of the frustration. In this scheme, both the welfare and agency interests refer to reasons why a being is vulnerable, while frustrations of those interests outline circumstances of manifestations of vulnerability. The paradigmatic member of the human species represents a reference point for determining whether a certain influence can count as frustration of welfare interests, i.e. result in harming the being. Frustrating someone's agency interests partially overlaps with results concerning frustrating welfare interests, however it also covers cases of going against a person's conception of the good, i.e. results in wrongs without inducing actual physical or mental harm. In this case, the only manifestations of vulnerability which could count as morally problematic would be those which involved a moral agent who had power over the frustration or satisfaction of the interests in question and failed to take them into fair consideration (Martin et al., 2014).

On the other side of the spectrum, Martha Albertson Fineman (2008) understands vulnerability as associated with the body, which entails the ever-present possibility of harm and injury. Despite the universal character of vulnerability, our position in a multilayered net of relationships makes our vulnerabilities very particular. Therefore, vulnerability must be analyzed with regard to its individual and institutional components (Fineman, 2008: 9-10). Fineman confronts her vulnerable subject with the liberal subject, arguing that the vulnerable subject approach, unlike the liberal one, is sensitive to varieties of changes that can incur during the course of life and make us dependent. However, in Fineman's account 'vulnerability' is not another or better term for 'dependency', because 'vulnerability' describes a state of constant possibility of harm. Being universal and inevitable, vulnerability is also shared and represents a factor for the initiation of a new equality movement in the aim of challenging unequal institutional arrangements (Fineman, 2008: 17). Fineman (2010) admits that the vulnerable subject approach has developed from exploration of rights part into research on human part in the human rights sphere. In her approach Fineman targets the myths of autonomy and independence and advocates for the recognition of the vulnerable and dependent nature of the human subject. The final goal is to replace the liberal subject with the vulnerable subject - a change that should, as Fineman hopes, provoke a deep transformation of state institutions and the establishment of a regime of equality (Fineman, 2010).

As already mentioned, the understanding of vulnerability as context-dependent hides a paradox: by leaving behind the account of vulnerability which presupposes identification of an individual with a certain feature and by becoming more sensitive to the constellation of 
specific circumstances, it has actually strengthened the central claim of the universalistic position (or the 'philosophical' perspective). However, as the definition of vulnerability that aims at justifying special protection (of those who are vulnerable) has to assume the existence of invulnerable subjects (those who are not vulnerable), it will in effect never conjoin with the understanding of vulnerability as a universal characteristic of human nature (every human being is by nature vulnerable). What would lead in that direction would be the assumption that certain circumstances only reveal our vulnerability, as suggested by Schroeder and Gefenas (2009). On the other hand, it seems arbitrary to think that our openness in a certain context can make us only victims of harm and wrongs. Therefore, Gilson proposes that vulnerability should be understood as a potential, literally as vulnerability (Gilson, 2011: 310-311). She wonders how vulnerability acquired the status of being solely a negative phenomenon and concludes that the ignorance of vulnerability as a shared, basic condition was generated through "the achievement of invulnerability as a desirable character trait and form of subjectivity" (Gilson, 2011: 312). According to Gilson (2011: 314), the ignorance of vulnerability is produced because we "disavow it as formative and significant" when realizing that invulnerability has greater social utility. This disavowal is thus a "form of cultivated ignorance rather than a conscious and deliberate rejection" (Gilson, 2011: 312). At this point Gilson's critique of the invulnerable subject takes issue with the dominant model of thinking and operating in a reductionist fashion (Gilson, 2011: 318). Gilson, as Henk ten Have (2015; 2016), promotes a universalistic view on vulnerability, where invulnerability figures as nothing more than a myth in modern society.

This is where the project of integration of the two perspectives on vulnerability calls for a redefinition of the conventional understanding of vulnerability. There is a certain amount of doubt on whether vulnerability consists only in openness to harm and wrongs. Gilson (2011) claims that such a reductionist view on vulnerability comes as a consequence of fostering the myth of invulnerability in modern society; vulnerability reduced to this form is based on the ignorance of shared vulnerability. The view on vulnerability as conditio humana is most commonly supported by evoking philosophical tradition. Vulnerability in this sense is considered as a part of (human) embodiment and hence mortality. As such, we cannot hope to eliminate it as it represents a constitutional element of what we are: weak, fragile, and imperfect. Henk ten Have (2015) has reminded us of philosophical anthropology which, mostly represented by the writings of Gehlen, has turned away from explaining the "natural superiority' of humankind and focused on intrinsic human deficiencies. Rather than being a pathology, vulnerability is here understood as an essential positive impulse of human development (ten Have, 2015: 403).

\section{CONCLUSION}

Martin et al. (2014) may have a point when claiming that the conflict between two views - the view that vulnerability encompasses everyone and the view that restricts it just to those requiring special protection - represents a philosophical pseudo problem. However, as they support their claim by referring to the likelihood of manifestations of vulnerability, they do not question the presupposed "negativity" of vulnerability. This negativity is generally understood as deficiency, dependency, or basically any fragility and weakness that a being might possess or, more precisely, suffer from. As such, vulnerability has to be eliminated or at least minimized, and the vulnerable should be protected. However, both 
scholarly literature and relevant ethics documents have troubles in defining who the vulnerable are and how they should be recognized. Attempts to cover all possible manifestations of vulnerability, i.e. to provide a safety net of special protection to all the vulnerable, have led to the conclusion that we are all open to harm and wrongs. That is a problematic situation for employing measures of special protection. There is absolutely no doubt that subjects who are exposed to harm and wrongs have to be protected. However, this is not the only side to vulnerability. In this text, I have tried to show where the differences between the two perspectives on vulnerability lie. My conclusion is that these two perspectives only reflect two different views on vulnerability: one that sees it as a solely negative, and the other which is sensitive to the complexity of (human) vulnerability and recognizes its potential, or even necessity, for our functioning in the world. The two perspectives meet at a point where vulnerability regains its status as, in Gilson words, an ability that can both limit and enable us, as a condition of openness to being affected both in a positive and negative way. This approach acknowledges the fact that some subjects are indeed affected in a negative way, and that such manifestations of vulnerability can (and should) be minimalized by society. On the other hand, it also acknowledges the power of vulnerability in establishing social contacts, fostering human development and in the construction of compassion, solidarity, and humanity itself.

\section{REFERENCES}

Butler, J. (2004). Precarious Life. The Power of Mourning and Violence, Verso, New York.

CIOMS (Council for International Organizations of Medical Sciences) in collaboration with WHO (World Health Organization) (2002). International Ethical Guidelines for Biomedical Research Involving Human Subjects, CIOMS: Geneva.

Coleman, C.H. (2009). Vulnerability as a Regulatory Category in Human Subject Research, Journal of Law, Medicine \& Ethics, Vol. 37, No. 1, 2009, pp. 12-18.

Declaration of Helsinki, In Wiesing, U.; Parsa-Parsi, R.W.; Kloiber, O. (eds.) (2014). The World Medical Association; Declaration of Helsinki, 1964-2014, 50 Years of Evolution of Medical Research Ethics, The World Medical Association, Ferney-Voltaire Cedex, France.

Denny, C.C.; Grady, C. (2007). Clinical Research with Economically Disadvantaged Populations, Journal of Medical Ethics, Vol. 33, 2007, pp. 382-385.

Fineman, M.A. (2008). The Vulnerable Subject: Anchoring Equality in the Human Condition, Yale Journal of Law \& Feminism, Vol. 20, No. 1, 2008; Emory Public Law Research Paper No. 8-40. Available at SSRN: https://ssrn.com/abstract=1131407

Fineman, M.A. (2010). The Vulnerable Subject and the Responsive State, Emory Law Journal, Vol. 60; Emory Public Law Research Paper No. 10-130. Available at SSRN: https://ssrn.com/abstract=1694740

Forster, H.P.; Emanuel, E.; Grady, C. (2001). The 2000 Revision of the Declaration of Helsinki: A Step Forward or More Confusion?, Lancet, Vol. 358, No. 9291, October 2001, pp. 1449-1453.

Gilson, E. (2011). Vulnerability, Ignorance, and Oppression, Hypatia, Vol. 26, No. 2 (Spring, 2011), pp. 308332.

Grady, C. (2009). Vulnerability in Research: Individuals with Limited Financial and/or Social Resources, Journal of Law, Medicine \& Ethics, Vol. 37, No. 1, Spring 2009, pp. 19-27.

Hoffmaster, B. (2006).What Does Vulnerability Mean?, The Hastings Center Report, Vol. 36, No. 2, 2006 , pp. $38-45$.

Hurst, S.A. (2008). Vulnerability in Research and Health Care; Describing the Elephant in the Room?, Bioethics, Vol. 22, No. 4, May 2008, pp. 191-202.

Kemp, P.; Rendtorff, J.D. (2008). The Barcelona Declaration. Towards an Integrated Approach to Basic Ethical Principles, Synthesis philosophica, Vol. 46, No. 2, 2008, pp. 239-251.

Kottow, M.H. (2005). Vulnerability: What Kind of Principle Is It?, Medicine, Health Care and Philosophy, Vol. 7, No. 3, 2005, pp. 281-287.

Lange, M.M.; Rogers, W.; Dodds, S. (2013). Vulnerability in Research Ethics: A Way Forward, Bioethics, Vol. 27, No. 6, 2013, pp. 333-340. 
Levine, C.; Faden, R.; Grady, C., Hammerschmidt, D.; Eckenwiler, L. (2004). The Limitations of "Vulnerability" as a Protection for Human Research Participants, American Journal of Bioethics, Vol. 4, No. 3, Summer 2004, pp. 44-49.

Lyerly, A.D.; Little, M.O.; Faden, R. (2008). The Second Wave: Toward Responsible Inclusion of Pregnant Women in Research, International Journal of Feminist Approaches to Bioethics, Vol. 1, No. 2, Fall 2008, pp. $5-22$.

Luna, F. (2009). Elucidating the Concept of Vulnerability: Layers not Labels, International Journal of Feminist Approaches to Bioethics, Vol. 2, No. 1, 2009, pp. 121-139.

Macklin, R. (2003). Bioethics, Vulnerability, and Protection, Bioethics, Vol. 17, No. 5-6, 2003, pp. $472-486$.

Martin, A.K; Tavaglione, N.; Hurst, S. (2014). Resolving the Conflict: Clarifying 'Vulnerability' in Health Care Ethics, Kennedy Institute of Ethics Journal, Vol. 24, No. 1, March 2014, pp. 51-72.

National Commission for the Protection of Human Subjects of Biomedical and Behavioral Research. 1979. The Belmont Report: Ethical Principles and Guidelines for the Protection of Human Subjects of Research, Washington, DC: Department of Health, Education and Welfare. Available at: http://www.hhs.gov/ohrp/humansubjects/guidance/belmont.html. Accessed September 9, 2013.

Patrão Neves, M. (2009). Article 8: Respect for Human Vulnerability and Personal Integrity. In ten Have, H.; Jean, M.S. (eds.), The UNESCO Universal Declaration on Bioethics and Human Rights: Background, Principles and Application, UNESCO, Paris, pp. 155-164.

Rendtorff J.D. (2002). Basic Ethical Principles in European Bioethics and Biolaw: Autonomy,

Dignity, Integrity and Vulnerability-Towards a Foundation of Bioethics and Biolaw, Medicine, Health Care and Philosophy, Vol. 5, No. 3, 2002, pp. 235-244.

Ricœur, P. (2007). Reflections on the Just, Chicago and London: University of Chicago Press.

Rogers, W.; Mackenzie, C.; Dodds, S. (2012). Why Bioethics Needs a Concept of Vulnerability, International Journal of Feminist Approaches to Bioethics, Vol. 5, No. 2, Fall 2012, pp. 11-38.

Ruof, M.C. (2004). Vulnerability, Vulnerable Populations, and Policy (Scope note 44), Bioethics Research Library, The Joseph and Rose Kennedy Institute of Ethics, Georgetown University, Washington. Available at: https://repository.library.georgetown.edu/bitstream/handle/10822/556901/sn44.pdf;sequence=4

Schroeder, D.; Gefenas, E. (2009). Vulnerability: Too Vague and Too Broad?, Cambridge

Quarterly of Healthcare Ethics, Vol. 18, No. 2, 2009, pp. 113-121.

Shi, L. (2001). The Convergence of Vulnerable Characteristics and Health Insurance in the US, Social Science \& Medicine, Vol. 53, 2001, pp. 519-529.

Shi, L.; Stevens, G.D. (2010). Vulnerable Populations in the United States, John Wiley \& Sons.

Sten Have, H. (2015). Respect for Human Vulnerability: The Emergence of a New Principle in

Bioethics, Journal of Bioethical Inquiry, Vol. 12, No. 3, September 2015, pp. 395-408.

Sten Have, H. (2016). Vulnerability. Challenging Bioethics, Routledge, London and New York.

Turner, B.S. (2006). Vulnerability and Human Rights, Penn State University Press, Philadelphia

Turner, B.S.; Dumas A. (2013). Vulnerability, Diversity and Scarcity: On Universal Rights, Medicine, Health Care and Philosophy, Vol. 16, No. 4, November 2013, pp. 663-670.

UNESCO (United Nations Educational, Scientific and Cultural Organization) (2005). Universal Declaration on Bioethics and Human Rights. Available at: http://unesdoc.unesco.org/images/0014/001461/146180E.pdf. Accessed August 28, 2013

UNESCO (United Nations Educational, Scientific and Cultural Organization) (2013). The Principle of Respect for Human Vulnerability and Personal Integrity of the International Bioethics Committee of UNESCO (IBC). Available at: http://unesdoc.unesco.org/images/0021/002194/219494E.pdf. Accessed August 28, 2013.

Wild, V. (2012). How Are Pregnant Women Vulnerable Research Participants?, International Journal of Feminist Approaches to Bioethics, Vol. 5, No. 2, Fall 2012, pp. 82-104.

Wrigley, A. (2015). An Eliminativist Approach to Vulnerability, Bioethics, Vol. 29, No. 7, September 2015, pp. $478-487$.

Zagorac, I. (2016). How Should We Treat the Vulnerable? Qualitative Study of Authoritative Ethics Documents, Journal of Health Care for the Poor and Underserved, Vol. 27, No. 4, 2016, pp. 1655-1671. 


\section{KAKVA RANJIVOST? ČIJA RANJIVOST? KONFLIKT RAZUMEVANJA U RASPRAVI O RANJIVOSTI}

Namera teksta je da se istraži prividnu poteškoću u komunikaciji između dvaju razumevanja ranjivosti: onog koje tvrdi da je ranjivost sastavni deo conditio humana, karakteristika blisko povezana sa činjenicom (ljudske) telesnosti i smrtnosti, te drugog, koje zagovara ekskluzivnost ranjivosti na način da je želi ograničiti samo na one koji su , više nego uobičajeno ranjivi“. U prvome delu teksta skiciraju se osnovni izvori spora između ovih dvaju razumevanja ranjivosti, onako kako ih se može iščitati iz naučne literature i relevantnih etičkih dokumenata. Teza teksta je da se konflikt shvatanja može razrešiti ako se koncept ranjivosti razume u svojoj kompleksnosti, pre nego reduciran na negativne aspekte. Kako bi se utemeljila ova teza, u drugome delu teksta istražuju se mogući elementi koncepta neranjivosti. U završnome delu razmatraju se tri pokušaja razrešenja konflikta. Zagovara se onaj koji poziva na redefinisanje konvencionalnog razumevanja ranjivosti.

Ključne reči: ranjivost, konflikt, mit o neranjivosti, negativnost 